\title{
Fine-Grained Nociceptive Maps in Primary Somatosensory Cortex
}

\author{
Flavia Mancini, ${ }^{1,2 \star}$ Patrick Haggard, ${ }^{1 \star}$ Gian Domenico Iannetti, ${ }^{2}$ Matthew R. Longo, ${ }^{3}$ and Martin I. Sereno ${ }^{4}$ \\ ${ }^{1}$ Institute of Cognitive Neuroscience, University College London, London WC1N 3AR, United Kingdom, ${ }^{2}$ Neuroscience, Physiology and Pharmacology \\ Department, University College London, London WC1E 6BT, United Kingdom, ${ }^{3}$ Department of Psychological Sciences, Birkbeck, University of London, \\ London WC1E 7HX, United Kingdom, and 4Birkbeck/University College London Neuroimaging Centre, London WC1H 0AP, United Kingdom
}

Topographic maps of the receptive surface are a fundamental feature of neural organization in many sensory systems. While touch is finely mapped in the cerebral cortex, it remains controversial how precise any cortical nociceptive map may be. Given that nociceptive innervation density is relatively low on distal skin regions such as the digits, one might conclude that the nociceptive system lacks fine representation of these regions. Indeed, only gross spatial organization of nociceptive maps has been reported so far. However, here we reveal the existence of fine-grained somatotopy for nociceptive inputs to the digits in human primary somatosensory cortex (SI). Using painful nociceptive-selective laser stimuli to the hand, and phase-encoded functional magnetic resonance imaging analysis methods, we observed somatotopic maps of the digits in contralateral SI. These nociceptive maps were highly aligned with maps of non-painful tactile stimuli, suggesting comparable cortical representations for, and possible interactions between, mechanoreceptive and nociceptive signals. Our findings may also be valuable for future studies tracking the time course and the spatial pattern of plastic changes in cortical organization involved in chronic pain.

\section{Introduction}

Topographic maps are a fundamental feature of most sensory systems, and are among the best known and widespread aspects of neural organization in the cerebral cortex (Thivierge and Marcus, 2007). While touch is mapped with exquisite precision in primary somatosensory cortex (SI) (Kaas et al., 1979; Maldjian et al., 1999), the spatial organization of the nociceptive system is controversial. In particular, it remains debated how precise any cortical nociceptive map may be.

Fine-grained topographic neural organization within SI is thought to allow precise spatial discrimination of tactile inputs (Kenshalo, 1968; Duncan and Boynton, 2007), and somatotopic maps of single digits have been repeatedly described (Kaas, 1983; Maldjian et al., 1999). Although there is both anatomical (Kenshalo et al., 1980; Gingold et al., 1991; Dum et al., 2009) and physiological (Treede et al., 1999; Duerden and Albanese, 2011; Valentini et al., 2012) evidence of nociceptive projections to SI, their spatial organization is less clear, and only broad somatotopies for hand, face, and foot territories have been described in

Received June 28, 2012; revised Sept. 21, 2012; accepted 0ct. 2, 2012.

Author contributions: F.M., P.H., and M.I.S. designed research; F.M., P.H., G.D.I., M.R.L., and M.I.S. performed research; F.M. and M.I.S. analyzed data; F.M., P.H., G.D.I., M.R.L., and M.I.S. wrote the paper

This work was supported by Wellcome Trust Project Grant 094863/Z/10/Z to G.D.I. and P.H., and by NIH Grant R01 MH 081990 to M.I.S.P.H. is additionally supported by EU FP7 project VERE. G.D.I. is a University Research Fellow of The Royal Society, and acknowledges the support of the Biotechnology and Biological Sciences Research Council. M.I.S. is also supported by a Royal Society Wolfson Research Merit Award.

*F.M. and P.H. contributed equally to this work.

The authors declare no competing financial interests.

Correspondence should be addressed to Flavia Mancini, Institute of Cognitive Neuroscience, University College London, London WC1N 3AR, UK. E-mail: f.mancini@ucl.ac.uk.

DOI:10.1523/JNEUROSCI.3059-12.2012

Copyright $\odot 2012$ the authors $\quad 0270-6474 / 12 / 3217155-08 \$ 15.00 / 0$ humans (Andersson et al., 1997; Bingel et al., 2004a) and in monkeys (Kenshalo et al., 2000).

Interestingly, the distribution of mechanoreceptors across skin regions differs sharply from the distribution of nociceptors (McArthur et al., 1998; Johansson et al., 1999; Lauria, 1999; Lauria et al., 1999): nociceptive innervation density is poor in distal body territories such as the digital papillae, where mechanoreceptor density is highest (Arthur and Shelley, 1959; Kelly et al., 2005). In contrast to the tactile system, the nociceptive system is often considered to lack a fovea at the fingertips. Therefore, the existence of finely organized cortical maps of nociceptive input from single digits is unknown.

Previous investigations have been limited by technical and methodological difficulties. For example, traditional 3D group averaging analyses may fail to reveal small maps given variation in spatial organization of nociceptive responses between individuals (Bushnell et al., 1999; Baumgärtner et al., 2010). We adapted a phase-encoded functional magnetic resonance imaging (fMRI) technique originally created to map the visual field (Sereno et al., 1995) to map the pain field.

Specifically, we studied the topographical organization of brain responses to radiant heat delivered to the fingers, using a $\mathrm{Nd}$ :YAP laser to provide a nociceptive-specific somatosensory input without coactivation of tactile afferents (Iannetti et al., 2006). Surface-based Fourier methods (Sereno and Huang, 2006) identify areas with differential responses at the stimulation frequency (e.g., Fig. 1 a shows the raw blood oxygen level-dependent (BOLD) signal elicited by the stimulation in a voxel across 9 cycles). These Fourier methods were used to compare somatotopic maps in SI elicited by nociceptive $\mathrm{A} \delta$ input inducing painful 
a
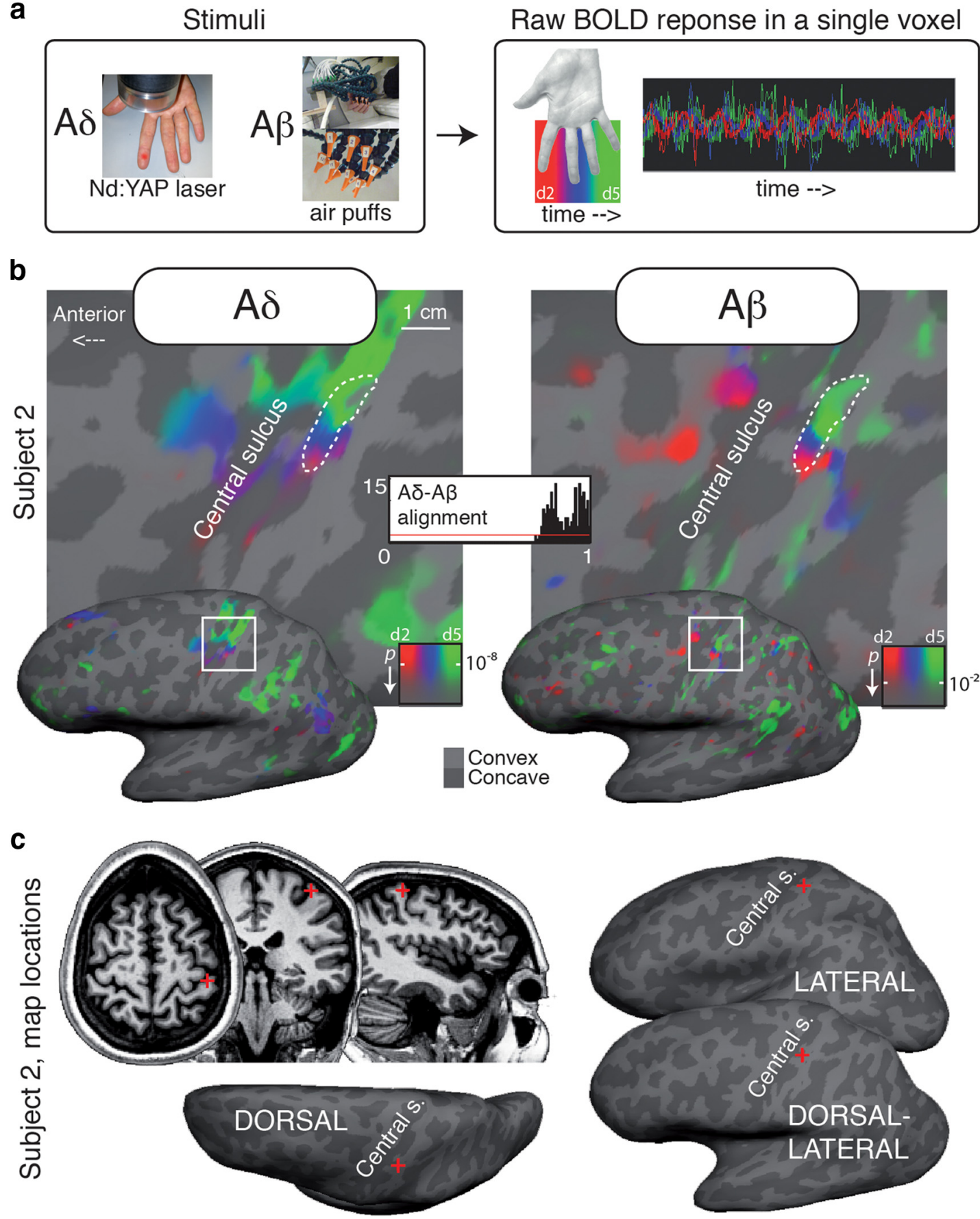

Figure 1. $\quad \boldsymbol{a}$, Phase-encoded protocol and raw BOLD response in one voxel. The color coding scheme used for A $\delta$ (laser) and A $\beta$ (air puffs) maps in Figures $1-3$ is shown in $\boldsymbol{a} . \boldsymbol{b}, \mathrm{Aligned} A \delta$ (laser) and $A \beta$ (air puffs) maps for a single subject (subject 2, dorsolateral view). Thick dashed white contours outline a region of interest defined as the connected surface patch of $S I$ vertices with significant periodic response to both $A \delta$ and $A \beta$ stimulation. $A$ similar alignment is evident for every color, representing stimulation to the digits (d2- $d 5$ ). The alignment index histogram shows the distribution of agreement in phase angle for each surface vertex within the dashed contour ( $1=$ max alignment). The red line indicates the distribution of the alignment index that would be expected if the two maps were completely uncorrelated. c, Location of the two maps (red cross) in an illustrative single subject.

pinprick sensations (A $\delta$ maps) to those elicited by non-painful tactile input ( $\mathrm{A} \beta$ maps).

The established organization of somatotopic maps of innocuous mechanical input to SI, together with the exquisite spatial precision in discriminating tactile inputs, provides a crucial point of comparison with the still debated spatial organization of pain. We specifically test whether the response to A $\delta$ stimulation of single digits is precisely represented in the cortical fields immediately adjacent to the central sulcus.

\section{Materials and Methods}

\section{Participants}

Right-handed participants of either sex $(n=7)$ took part in 2-3 fMRI imaging sessions each. Each gave informed consent according to procedures approved by University College London ethics committee.

\section{Procedure}

Participants laid with their right hand supine outside the scanner bore, and wore earplugs throughout the experiment. Repeated cycles of nociceptive or tactile stimulation (in separate sessions) were delivered suc- 
cessively to the volar surface of digits 2-5 (Fig. 1a). During each cycle, the four digits were stimulated sequentially one after each other. The stimulation of each digit consisted of somatosensory stimuli being delivered randomly to several locations on the volar surface of the digits (see details in the next two sections). For nociceptive stimulation, 9 cycles of $56.9 \mathrm{~s}$ trains of 4-ms-long laser pulses were delivered in each run, at a frequency of 0.43 pulse/s. For tactile stimulation, 12 cycles of $42.7 \mathrm{~s}$ trains of 70 -mslong air puffs were administered in each run, at a frequency of 5.88 puffs/s.

To improve the signal-to-noise ratio, we averaged four functional runs for each subject (see Data acquisition and analysis).

In the same subjects, we compared nociceptive maps with tactile maps elicited by computer-controlled trains of air puff (Huang and Sereno, 2007) stimulation, delivered with similar procedures to the volar surface of the same digits (2-5).

\section{Air puff stimulation}

An air compressor in the scanner control room provided input to a 12-way solenoid manifold valve (Numatics) that was controlled by transistor-transistor logic pulses. Twelve plastic air tubes from the manifold valve passed through waveguides into the scanner room, where they connected to a block mounted beside the right hand, at the edge of the bore. The block served as a rigid base for 12 flexible tubes with nozzles (Loc-Line), flexibly arranged to direct $70 \mathrm{~ms}$ air puffs (input air-pressure 2-3 bar) at 3 locations on the center of each stimulated finger segment (d2-d5, Fig. 1a). Each air puff was perceived as a well localized and light touch on a specific finger location.

\section{Laser stimulation}

Radiant-heat stimuli were generated by an infrared neodymium yttrium aluminum perovskite (Nd:YAP) laser with a wavelength of $1.34 \mu \mathrm{m}$ (Electronical Engineering). Laser pulses activate directly nociceptive terminals in the most superficial skin layers (Baumgärtner et al., 2005; Iannetti et al., 2006). Laser pulses were directed at 12 possible locations on the glabrous skin of the fingers $(\mathrm{d} 2-\mathrm{d} 5,2$ locations per finger-segment, aligned along the proximo-distal plane). A He-Ne laser pointed to the targeted location. The laser pulse (4 ms duration) was transmitted via optic fiber, passing through the control room to the scanner room. Beam diameter at the target site was $\sim 7 \mathrm{~mm}$. Pulse energy was adjusted for each subject (between 3 and $3.25 \mathrm{~J}$ ) to elicit a clear pinprick painful sensation, related to the activation of $\mathrm{A} \delta$ fibers. The experimenter inside the MR scanner room checked, between successive MRI runs, that the stimuli were perceived as painful.

\section{Data acquisition and analysis}

Echoplanar images $\left(3.2 \times 3.2 \mathrm{~mm}^{2}\right.$ in-plane, 3.2-mm-thick slices, 256 volumes/run, 24 axial slices, flip $=90^{\circ}$, TE $=39 \mathrm{~ms}$, TR $=2 \mathrm{~s}, 64 \times 64$ matrix, bandwidth $=1474 \mathrm{~Hz} /$ pixel, data acquired with prospective motion correction) were collected during 4 runs (per modality) on a Siemens Avanto 1.5 T MRI scanner with a 32-channel head coil. Functional series were aligned and motion-corrected using the AFNI (Analysis of Functional NeuroImages) program 3dvolreg. To improve the signal-tonoise ratio, we combined four functional runs for each subject. To correct for systematic regional variations in the shape of the hemodynamic response function, we interleaved index-to-little and little-to-index progressions (two runs each), and then combined opposite-direction data by vector addition of the complex-valued signal (the strength and phase of the response at the stimulus frequency), after reversing the phase in the opposite direction.

For each subject, we used FreeSurfer to reconstruct the cortical surface from 1 to 2 registered MPRAGE scans $\left(1 \times 1 \times 1 \mathrm{~mm}\right.$, flip $=7^{\circ}$, TR $=$ $2730 \mathrm{~ms}, \mathrm{TI}=1000 \mathrm{~ms}, \mathrm{TE}=3.57 \mathrm{~ms}$, matrix $=256 \times 224 \times 160,190$ $\mathrm{Hz}$ /pixel). The last run of each functional session was a short-alignment MPRAGE acquired in the plane of the functional runs $(1 \times 1 \times 2 \mathrm{~mm}$, flip $=7, \mathrm{TE}=4 \mathrm{~ms}, \mathrm{TI}=1000 \mathrm{~ms}$, TR $=8.2 \mathrm{~ms}$, matrix $=256 \times 224 \times$ 88, mSENSE acceleration $=2 \times$, slab-selective excitation). The align scan was first registered to the high-resolution structural scan. Using this as a starting point, functional- to high-resolution alignment was then refined using manual blink comparison. Four runs were combined to increase signal-to-noise ratio (see above).
After removing the linear trend, functional data were analyzed using a Fourier transform, computed for the time series at each voxel fraction (vertex). We computed an $F$-ratio by comparing the power of the complex-valued signal at the stimulus frequency to the power of the noise (other frequencies). Very low frequencies and harmonics were excluded. The $F$-ratio was then converted to an uncorrected $p$ value by considering the degrees of freedom of the signal and noise. The phase angle was displayed using a continuous color scale (red to blue to green), whose saturation was masked by the $p$-value (see color bar insets in Figs. 1-3).

\section{Surface-based cross-subject average map}

To average maps across subjects, we first inflated each participant's cortical surface to a sphere, and then nonlinearly morphed it into alignment with an average spherical cortical surface using FreeSurfer (Fischl et al., 1999). This procedure maximizes alignment between sulci (including the central sulcus), while minimizing metric distortions across the surface. Complex-valued mapping signals were then combined across subjects on a vertex-by-vertex basis by vector averaging (Sereno and Huang, 2006), after reversing phase measures for sequences where stimuli were presented in little-index finger order. The vector sum strongly penalizes inconsistent phases across runs and corrects for stationary between-voxel differences in hemodynamic delay. Finally, an $F$-statistic was calculated using the raw amplitude of the stimulus-frequency response (Hagler et al., 2007) and rendered back onto the cortical surface of one subject.

Map alignment measures. To quantify the alignment between nociceptive and air puffs maps, we calculated alignment indices and circular correlation coefficients for each subject separately, as described previously (Sereno and Huang, 2006). Both measures were evaluated across a region of interest defined as a connected two-dimensional patch of surface vertices in SI that had a significant periodic response to both nociceptive and air puff stimuli. The alignment index of each pair of vertices was defined as

$$
\text { Alignment index }=1-\frac{|\Delta \phi|}{\pi}
$$

where $\Delta \Phi$ is the difference between the phase angle in the two datasets in radians. The index ranges from 0 ( $\pi$ offset, i.e., when one phase angle is on the little finger and the other is on the index finger) to 1 (where the phase angle at a vertex is identical in the two datasets). A histogram of alignment indices that is sharply peaked near 1 indicates strong alignment between two maps. Conversely, an uncorrelated map would result in a shallow uniform distribution of alignment indices, in which every bin has low frequency $(2 v / n$, where $v$ is the number of vertices and $n$ is the number of bins), illustrated by a red line in each alignment index histogram (Figs. 1b, 2, 3).

For each comparison, we calculated the average of the alignment indices, the circular correlation of vertex-by-vertex phase angles (after controlling for angle wraparound), and its significance. The quantitative agreement between the two maps is constrained by cross-session alignment accuracy, which is itself constrained by the voxel size of the functional scans. During registration, we subsampled each session's functional data to $1 \times 1 \times 1 \mathrm{~mm}$ and then did nearest neighbor smoothing to achieve subvoxel alignment accuracy to the single $1 \times 1 \times 1$ structural scan $(\sim 1.5 \mathrm{~mm})$.

Map location measures. For each subject separately, we calculated the centroid of each $\mathrm{A} \delta$ and $\mathrm{A} \beta$ map, as the surface vertex coordinate closest to the average of the vertex coordinates in a region of interest (ROI) defined as a connected two-dimensional patch of surface vertices in SI that had a significant periodic response to the stimuli. To allow across-subject comparisons, we used morphed spherical coordinates, displayed on a $2 \mathrm{D}$ plane tangential to the spherical surface. In addition, a similar centroid calculation was made for the average map. Note that the centroid of the average map (from Fig. 3) is not simply the mathematical average of centroids calculated from ROIs defined for individual subjects. The centroid of the average map was obtained as the average of the vertex coordinates within the $\mathrm{A} \delta$ and $\mathrm{A} \beta$ ROIs defined on the surface- 


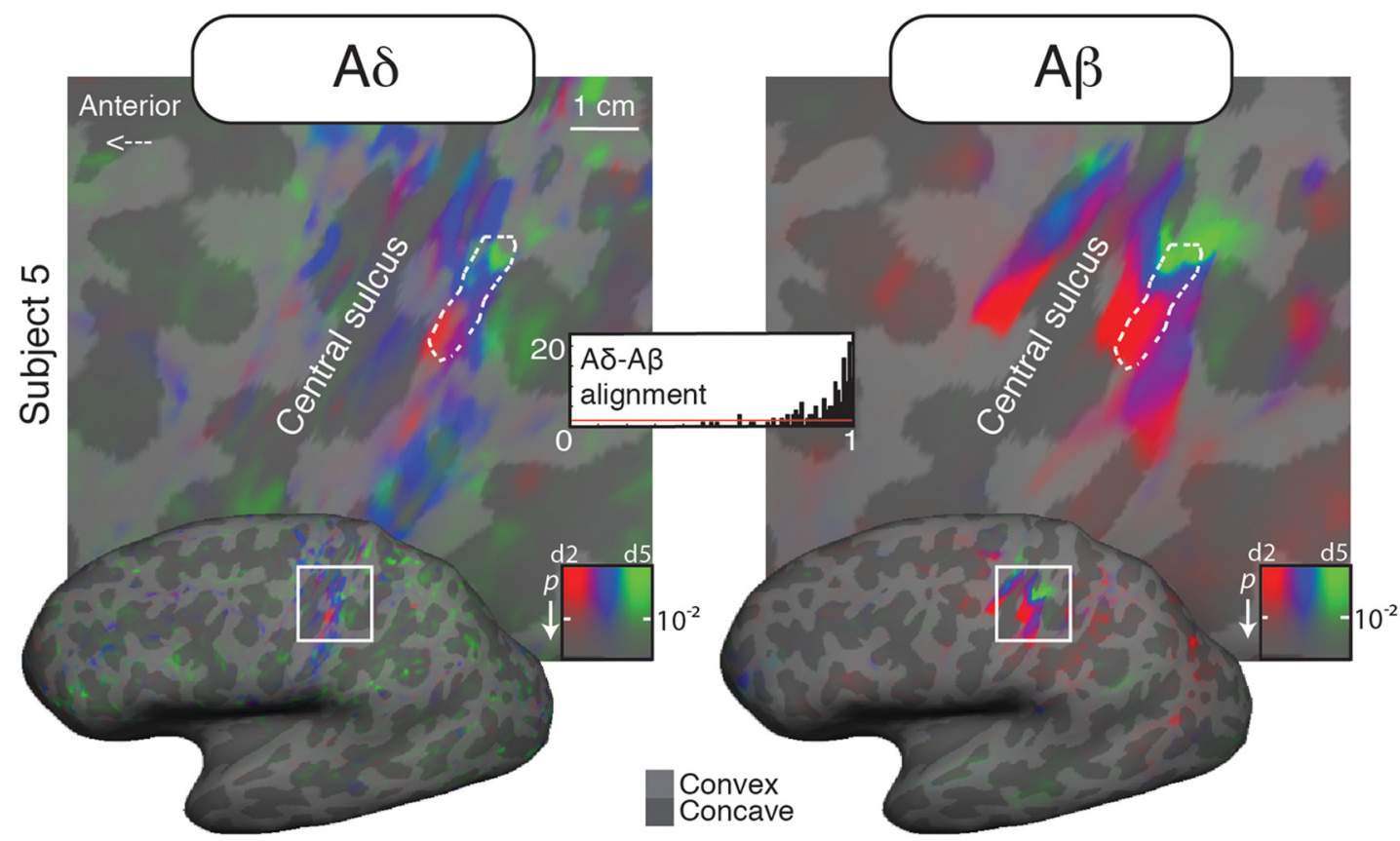

Figure 2. Aligned $A \delta$ (laser) and $A \beta$ (air puffs) maps for a single subject (subject 5, dorsolateral view).

based average of Figure 3 (see Surface-based cross-subject average map). Finally, spherical coordinates were linearly transformed into Talairach coordinates (Collins et al., 1994) with FreeSurfer.

\section{Results}

\section{Fine-grained nociceptive maps of the digits in SI}

For each subject, nociceptive stimulation of the fingers elicited a clear and strong somatotopic response within the hand area of the contralateral SI (BOLD response in two illustrative subjects, Figs. $1 b, 2)$. These nociceptive maps were located on the convexity of the central sulcus, in a region overlapping that activated by air-puff stimulation (Figs. 1c, 4).

We did not find any significant activation at the stimulus frequency in the ipsilateral hemisphere. Importantly, the Fourierbased methods used only show areas with differential responses at the stimulation frequency (Fig. 1a), while regions that respond to every laser pulse are not visible.

The map size was variable across individuals: in some subjects the nociceptive map was larger than the mechanical (Fig. 1 ), while in other subjects we observed the opposite pattern (Fig. 2).

\section{High alignment of nociceptive and tactile maps}

Within both $\mathrm{A} \delta$ and $\mathrm{A} \beta$ maps, the index finger was represented inferior to the little finger. Thus, nociceptive and tactile maps in contralateral SI have similar location and alignment (Figs. 1b, 2).

To quantitatively compare within-subject alignment between the two maps, we calculated an alignment index (Sereno and Huang, 2006) that ranged from 0 ( $\pi$ offset in response phase) to 1 (perfectly aligned) for each surface vertex in the hand area of the contralateral SI (dashed white line). In every subject the distribution of such alignment indices was strongly skewed toward 1 (aligned), and the phase angles of the two maps were highly correlated (all $p<10^{-10}$, Table 1 ).

Across-subjects map averages were performed with FreeSurfer by morphing individual brain surfaces into alignment with an average target brain, sampling the data onto a super-
Table 1. Vertex-by-vertex polar angle circular correlations and average alignment indices across the $A \delta$ and $A \boldsymbol{\beta}$ maps

\begin{tabular}{llll}
\hline Subject & Number of vertices & Circular correlation* & $\begin{array}{l}\text { Average Alignment } \\
\text { Indices }\end{array}$ \\
\hline 1 & 157 & 0.94 & 0.87 \\
2 & 198 & 0.93 & 0.88 \\
3 & 80 & 0.94 & 0.92 \\
4 & 73 & 0.99 & 0.95 \\
5 & 158 & 0.90 & 0.90 \\
6 & 107 & 0.86 & 0.77 \\
7 & 180 & 0.95 & 0.88 \\
Average (7) & 449 & 0.96 & 0.87 \\
\hline
\end{tabular}

${ }^{*} p<10^{-10}$.

tessellated icosahedron. The F-statistic was rendered back to the unfolded hemisphere of one subject (Fig. 3). Alignment histograms and correlations showed that the average fingers maps of tactile and nociceptive input were highly aligned, consistent with individual results (Table 1 ).

\section{Location of the centroids of $A \delta$ and $A \boldsymbol{\beta}$ maps in SI}

To investigate the locations of each individual participant's A $\delta$ and $\mathrm{A} \beta$ maps, we calculated the centroid of the region that showed strong somatotopic response to each type of stimulus. This operation was performed on the individual morphed spherical surface, to allow across-subjects comparisons. As shown in Figure 4, the relative locations of the $\mathrm{A} \delta$ and $\mathrm{A} \beta$ maps centroids varied across individuals, with no consistent offset between the two maps. For comparison, Figure 4 also shows the location of the average map, taken from Figure 3. The locations of our maps appear consistent with previous studies mapping $\mathrm{A} \beta$ to the digits (e.g., Gelnar et al., 1998; Maldjian et al., 1999; McGlone et al., 2002; Overduin and Servos, 2004; Nelson and Chen, 2008), and A $\delta$ input to the hand (Bingel et al., 2004a). 


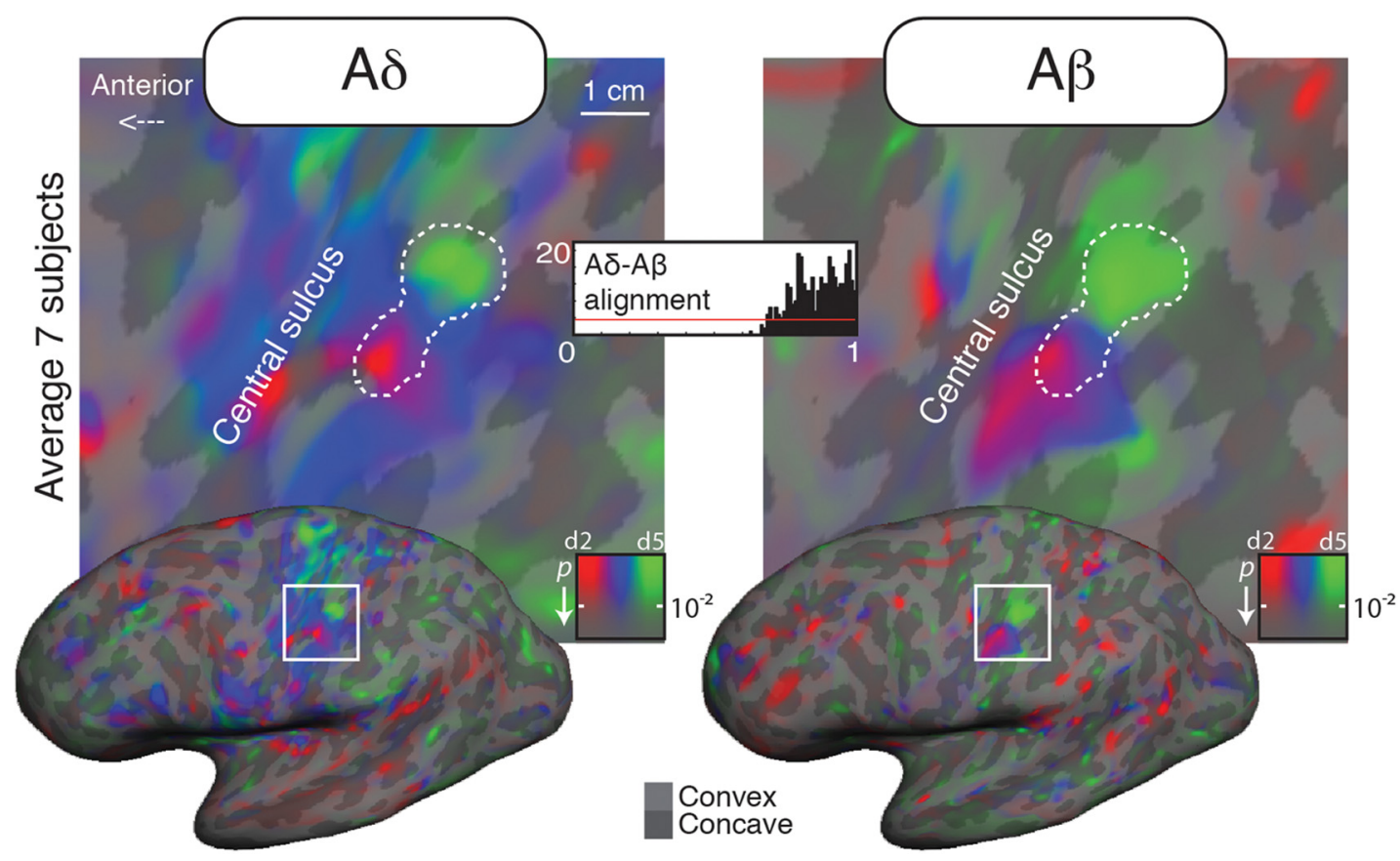

Figure 3. Surface-based average $A \delta$ (laser) and $A \beta$ (air puffs) maps from seven subjects (dorsolateral view). The complex-valued mapping data were averaged in a spherical surface coordinate system after morphing each subject's data into alignment with an average spherical sulcal pattern, and the $F$-statistics was rendered back onto the unfolded cortical surface of one subject.
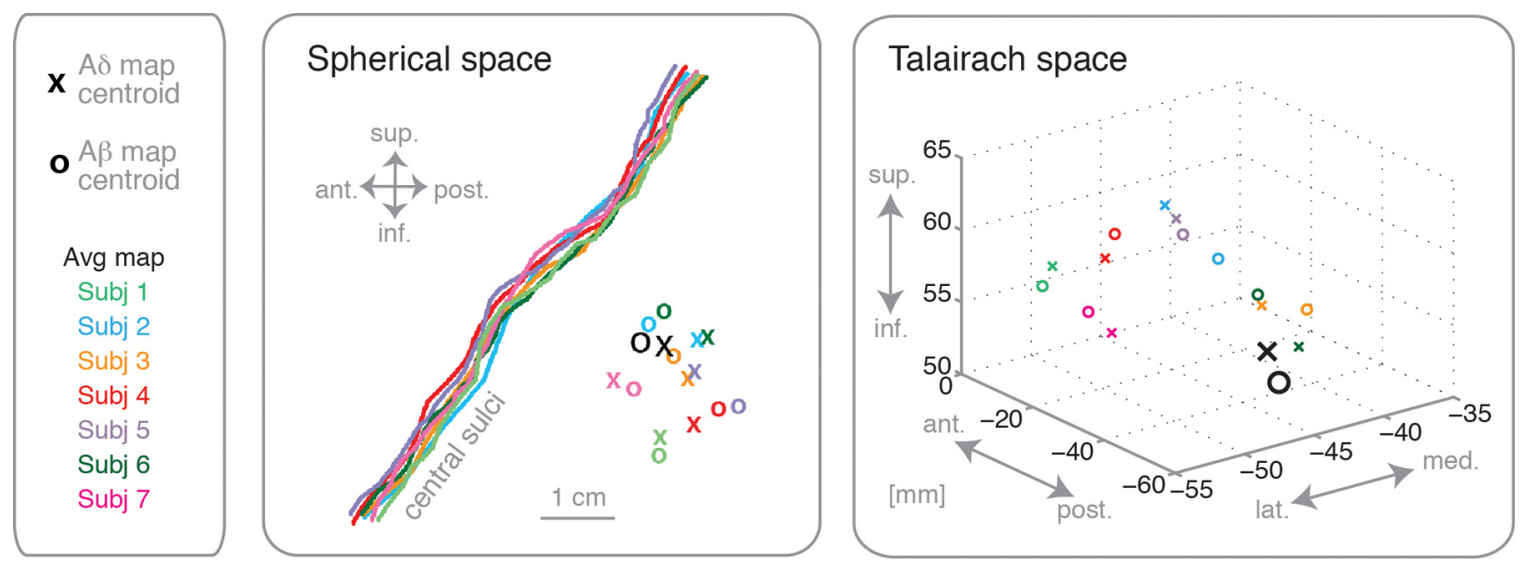

Figure 4. Map locations in spherical and Talairach space. For each subject, the central sulcus was identified and the location of the centroid of $A \delta$ (laser) and A $\beta$ (air puffs) maps was rendered onto a plane tangential to the morphed spherical surface. In addition, the centroids of the average maps of 7 subjects, taken from Figure 3, were displayed for comparison (see Materials and Methods for details). The centroids were plotted both in spherical space relative to the central sulcus, and in Talairach space (Collins et al., 1994).

\section{Discussion}

These results reveal that nociceptive input from each digit of the human hand is finely organized in SI, in a somatotopic fashion. Our nociceptive maps were highly aligned with tactile maps obtained by innocuous somatosensory stimuli in every subject. Importantly, the two maps were essentially colocated, since there was no systematic offset in the centroid location of one map relative to the other. We also noted some interindividual variability in map location. Traditional $3 \mathrm{D}$ group averaging analyses might therefore fail to reveal these relatively small A $\delta$ maps, which may explain inconsistencies in previous reports of nociceptive spatial organization in SI. Phaseencoded methods have allowed us to develop a new approach to somatotopic mapping of nociceptive input, thus providing a new quantitative marker of the spatial coding of pain in the human brain.
Somatotopic organization of tactile and nociceptive RFs has been described in the dorsal horn (Swett and Woolf, 1985), the lateral thalamus (Albe-Fessard et al., 1985; Lenz et al., 1994), putamen (Bingel et al., 2004b), SI (Lamour et al., 1983a,b; Andersson et al., 1997; Kenshalo et al., 2000; Bingel et al., 2004a), and operculo-insular cortex (Brooks et al., 2005; Mazzola et al., 2009; Baumgärtner et al., 2010). However, only gross somatotopy of the brain responses to nociceptive input has been observed in those studies. Reports of spatially precise cortical maps in monkeys are based on stimuli that simultaneously activate $\mathrm{A} \delta$ and $\mathrm{A} \beta$ fibers (Chen et al., 2011). While many studies examined the brain responses in SI to nociceptive-specific stimulation of the hand (Andersson et al., 1997; Kanda et al., 2000; Ploner et al., 2000; Timmermann et al., 2001; Bingel et al., 2004a; Liang et al., 2011; Zhang et al., 2012), no previous study, to our knowledge, has focused on 
the topographical organization of those responses within single hand digits. Our study reveals for the first time the existence of fine-grained nociceptive somatotopic maps in SI. Other studies focusing on different cortical regions might reveal somatotopic activations in other regions than SI.

The existence of fine-grained nociceptive maps of the digits in SI is remarkable, considering the available evidence of the anatomical distribution of nociceptive afferents in the periphery (McArthur et al., 1998; Johansson et al., 1999; Lauria, 1999; Lauria et al., 1999). Indeed, intraepidermal nerve fiber density in the human skin appears to decrease from proximal to distal body parts (Holland et al., 1997; McArthur et al., 1998; Johansson et al., 1999; Lauria et al., 1999; Sumner et al., 2003), and particularly along the hand to the digital papillae (Arthur and Shelley, 1959; Kelly et al., 2005). Conversely, afferents that respond to mechanical innocuous touch show an opposite organization. The somatosensory homunculus (Rasmussen and Penfield, 1947; Penfield and Rasmussen, 1950) shows enlarged representation of the digits relative to proximal skin regions. More recently, fMRI studies have confirmed enlarged cortical territories correlate with discrimination thresholds (Duncan and Boynton, 2007), confirming classical psychophysical measures of acuity (Boring, 1942).

Given the evidence of relatively poor nociceptive innervation density on the digits (Arthur and Shelley, 1959; Kelly et al., 2005) and the present finding of aligned $\mathrm{A} \delta$ and $\mathrm{A} \beta$ maps, we speculate that the fine nociceptive spatial resolution we have observed in SI might result from complex interactions between tactile and nociceptive central projections. The first candidate for such interactions may be the dorsal horn where, beside high-threshold nociceptive-specific (NS) neurons, wide dynamic range (WDR) neurons respond to noxious stimulation and also to weak, mechanical stimuli such as hair movement (Maixner et al., 1986). WDR projections might contribute to the striking alignment of laser/A $\delta$ and airpuffs/A $\beta$ maps we found. Vertical excitatory interneurons may allow connections between layers I-III, at least in rats' dorsal horn (Maxwell et al., 2007; Todd, 2010; Yasaka et al., 2010). The function of these vertical interactions is not fully understood, but it might favor communication between somatosensory submodalities. Other sites of possible interactions are the thalamus (Wepsic, 1966), and the postcentral gyrus. Modular, columnar segregation in primate postcentral areas has been reported only for mechanoreceptive afferents (Dykes et al., 1980; Sur et al., 1984; Friedman et al., 2004), but not for cortical neurons that respond to noxious stimuli (Mountcastle and Powell, 1959; Kenshalo and Isensee, 1983; Kenshalo et al., 2000). In particular, NS neurons in area 1 of SI seem to be vertically organized, and most prevalent in cortical layers III-IV (Kenshalo et al., 2000). Kenshalo et al. (2000) reported the distributed presence in SI of WDR neurons, preferentially responding to noxious thermal stimulation, and with receptive fields overlapping those of NS neurons. Intermixed populations of mechanical and nociceptive neurons might be linked by local intrinsic connections within SI, thus allowing interactions between somatosensory submodalities. Accordingly, several neuroimaging studies report interactions between $\mathrm{A} \delta$ and $\mathrm{A} \beta$ responses in SI (Ploner et al., 2004; Inui et al., 2006).

Separate multiple somatotopic maps of mechanoreceptive afferents are present in areas 3b, 1, and 2 of SI (Kaas et al., 1979; Krubitzer and Kaas, 1990; Friedman et al., 2004). Our neuroimaging method cannot readily separate the responses from these different cortical fields. However, it is noteworthy that our A $\delta$ and $\mathrm{A} \beta$ maps of the digits were highly aligned, without any consistent offset in their centroids across individuals (Fig. 4). Previous studies in humans directly comparing locations of SI responses to nociceptive and tactile stimuli to the hand reported that the nociceptive territory was located slightly medial to the tactile territory (Coghill et al., 1994; Iadarola et al., 1998; Ploner et al., 2000).

Although the functional role of topographic maps in sensory systems is still debated (Kaas, 1997; Weinberg, 1997), a large body of evidence suggests that topographic mapping brings computational advantages and plays an important role in the organization of sensory processing and cognition (for a review, see Thivierge and Marcus, 2007). Topographic organization of SI seems to underlie tactile spatial acuity (Kenshalo, 1968). Our results show similar alignment of $A \delta$ and $A \beta$ maps of the digits. Although psychophysical studies of spatial resolution for pain on the fingertips are lacking, the spatial precision for pain, as assessed by one-point localization tasks, approaches that of touch in the hairy skin of the hand (Schlereth et al., 2001; Mancini et al., 2011). This suggests that the spatial-discriminative aspects of tactile and pain perception may share a common neural substrate, and raises the intriguing possibility that $\mathrm{A} \delta$ and $\mathrm{A} \beta$ maps might interact.

There has been extensive debate in the literature about whether pain is a purely interoceptive sensation (Craig, 2003) or an exteroceptive form of perception (Price et al., 2003). By showing that sensations elicited by $\mathrm{A} \delta$ input have an organization similar to that of unambiguously exteroceptive touch, our results are consistent with the view of pain having an exteroceptive aspect. Clearly, however, they do not exclude that pain has an interoceptive, or even emotional, function.

Finally, maladaptive reorganization of cortical topographic connectivity is often associated with chronic pain (Flor et al., 1995; Juottonen et al., 2002; Maihöfner et al., 2003), highlighting the role of sensory maps in pain perception. In the context of clinical research, understanding and tracking plastic changes in somatosensory maps has proven challenging because a precise measure of the spatial resolution of these maps was lacking. Here we demonstrated that precise somatotopic maps related to pain can be revealed using phase-encoded methods for fMRI, providing novel, quantitative markers of the spatial coding of pain in the human brain. These markers could be a valuable measure of cortical organization in clinical pain syndromes, which is specifically targeted in treatments that use sensory discrimination training (Flor et al., 2001; Moseley et al., 2008) and noninvasive brain stimulation techniques (Fregni et al., 2007).

\section{References}

Albe-Fessard D, Berkley KJ, Kruger L, Ralston HJ 3rd, Willis WD Jr (1985) Diencephalic mechanisms of pain sensation. Brain Res 356: 217-296. Medline

Andersson JL, Lilja A, Hartvig P, Långström B, Gordh T, Handwerker H, Torebjörk E (1997) Somatotopic organization along the central sulcus, for pain localization in humans, as revealed by positron emission tomography. Exp Brain Res 117:192-199. CrossRef Medline

Arthur RP, Shelley WB (1959) The innervation of human epidermis. J Invest Dermatol 32:397-411. CrossRef Medline

Baumgärtner U, Cruccu G, Iannetti GD, Treede RD (2005) Laser guns and hot plates. Pain 116:1-3. CrossRef Medline

Baumgärtner U, Iannetti GD, Zambreanu L, Stoeter P, Treede RD, Tracey I (2010) Multiple somatotopic representations of heat and mechanical pain in the operculo-insular cortex: a high-resolution fMRI study. J Neurophysiol 104:2863-2872. CrossRef Medline 
Bingel U, Lorenz J, Glauche V, Knab R, Gläscher J, Weiller C, Büchel C (2004a) Somatotopic organization of human somatosensory cortices for pain: a single trial fMRI study. Neuroimage 23:224-232. CrossRef Medline

Bingel U, Gläscher J, Weiller C, Büchel C (2004b) Somatotopic representation of nociceptive information in the putamen: an event-related fMRI study. Cereb Cortex 14:1340-1345. CrossRef Medline

Boring EG (1942) Sensation and perception in the history of experimental psychology. New York: Appleton-Century.

Brooks JC, Zambreanu L, Godinez A, Craig AD, Tracey I (2005) Somatotopic organisation of the human insula to painful heat studied with high resolution functional imaging. Neuroimage 27:201-209. CrossRef Medline

Bushnell MC, Duncan GH, Hofbauer RK, Ha B, Chen JI, Carrier B (1999) Pain perception: is there a role for primary somatosensory cortex? Proc Natl Acad Sci U S A 96:7705-7709. CrossRef Medline

Chen LM, Dillenburger BC, Wang F, Friedman RM, Avison MJ (2011) High-resolution functional magnetic resonance imaging mapping of noxious heat and tactile activations along the central sulcus in New World monkeys. Pain 152:522-532. CrossRef Medline

Coghill RC, Talbot JD, Evans AC, Meyer E, Gjedde A, Bushnell MC, Duncan GH (1994) Distributed processing of pain and vibration by the human brain. J Neurosci 14:4095-4108. Medline

Collins DL, Neelin P, Peters TM, Evans AC (1994) Automatic 3D intersubject registration of MR volumetric data in standardized Talairach space. J Comput Assist Tomogr 18:192-205. CrossRef Medline

Craig AD (2003) A new view of pain as a homeostatic emotion. Trends Neurosci 26:303-307. CrossRef Medline

Duerden EG, Albanese MC (2011) Localization of pain-related brain activation: a meta-analysis of neuroimaging data. Hum Brain Mapp. Advance online publication. Retrieved November 1, 2012. doi:10.1002/ hbm.21416. CrossRef

Dum RP, Levinthal DJ, Strick PL (2009) The spinothalamic system targets motor and sensory areas in the cerebral cortex of monkeys. J Neurosci 29:14223-14235. CrossRef Medline

Duncan RO, Boynton GM (2007) Tactile hyperacuity thresholds correlate with finger maps in primary somatosensory cortex (S1). Cereb Cortex 17:2878-2891. CrossRef Medline

Dykes RW, Rasmusson DD, Hoeltzell PB (1980) Organization of primary somatosensory cortex in the cat. J Neurophysiol 43:1527-1546. Medline

Fischl B, Sereno MI, Tootell RB, Dale AM (1999) High-resolution intersubject averaging and a coordinate system for the cortical surface. Hum Brain Mapp 8:272-284. CrossRef Medline

Flor H, Elbert T, Knecht S, Wienbruch C, Pantev C, Birbaumer N, Larbig W, Taub E (1995) Phantom-limb pain as a perceptual correlate of cortical reorganization following arm amputation. Nature 375:482-484. CrossRef Medline

Flor H, Denke C, Schaefer M, Grüsser S (2001) Effect of sensory discrimination training on cortical reorganisation and phantom limb pain. Lancet 357:1763-1764. CrossRef Medline

Fregni F, Freedman S, Pascual-Leone A (2007) Recent advances in the treatment of chronic pain with non-invasive brain stimulation techniques. Lancet Neurol 6:188-191. CrossRef Medline

Friedman RM, Chen LM, Roe AW (2004) Modality maps within primate somatosensory cortex. Proc Natl Acad Sci U S A 101:12724-12729. CrossRef Medline

Gelnar PA, Krauss BR, Szeverenyi NM, Apkarian AV (1998) Fingertip representation in the human somatosensory cortex: an fMRI study. Neuroimage 7:261-283. CrossRef Medline

Gingold SI, Greenspan JD, Apkarian AV (1991) Anatomic evidence of nociceptive inputs to primary somatosensory cortex: relationship between spinothalamic terminals and thalamocortical cells in squirrel monkeys. J Comp Neurol 308:467-490. CrossRef Medline

Hagler DJ Jr, Riecke L, Sereno MI (2007) Parietal and superior frontal visuospatial maps activated by pointing and saccades. Neuroimage 35:1562-1577. CrossRef Medline

Holland NR, Stocks A, Hauer P, Cornblath DR, Griffin JW, McArthur JC (1997) Intraepidermal nerve fiber density in patients with painful sensory neuropathy. Neurology 48:708-711. CrossRef Medline

Huang RS, Sereno MI (2007) Dodecapus: an MR-compatible system for somatosensory stimulation. Neuroimage 34:1060-1073. CrossRef Medline
Iadarola MJ, Berman KF, Zeffiro TA, Byas-Smith MG, Gracely RH, Max MB, Bennett GJ (1998) Neural activation during acute capsaicin-evoked pain and allodynia assessed with PET. Brain 121:931-947. CrossRef Medline

Iannetti GD, Zambreanu L, Tracey I (2006) Similar nociceptive afferents mediate psychophysical and electrophysiological responses to heat stimulation of glabrous and hairy skin in humans. J Physiol 577:235248. CrossRef Medline

Inui K, Tsuji T, Kakigi R (2006) Temporal analysis of cortical mechanisms for pain relief by tactile stimuli in humans. Cereb Cortex 16: 355-365. Medline

Johansson O, Wang L, Hilliges M, Liang Y (1999) Intraepidermal nerves in human skin: PGP 9.5 immunohistochemistry with special reference to the nerve density in skin from different body regions. J Peripher Nerv Syst 4:43-52. Medline

Juottonen K, Gockel M, Silén T, Hurri H, Hari R, Forss N (2002) Altered central sensorimotor processing in patients with complex regional pain syndrome. Pain 98:315-323. CrossRef Medline

Kaas JH (1983) What, if anything, is SI? Organization of first somatosensory area of cortex. Physiol Rev 63:206-231. Medline

Kaas JH (1997) Topographic maps are fundamental to sensory processing. Brain Res Bull 44:107-112. CrossRef Medline

Kaas JH, Nelson RJ, Sur M, Lin CS, Merzenich MM (1979) Multiple representations of the body within the primary somatosensory cortex of primates. Science 204:521-523. CrossRef Medline

Kanda M, Nagamine T, Ikeda A, Ohara S, Kunieda T, Fujiwara N, Yazawa S, Sawamoto N, Matsumoto R, Taki W, Shibasaki H (2000) Primary somatosensory cortex is actively involved in pain processing in human. Brain Res 853:282-289. CrossRef Medline

Kelly EJ, Terenghi G, Hazari A, Wiberg M (2005) Nerve fibre and sensory end organ density in the epidermis and papillary dermis of the human hand. Br J Plast Surg 58:774-779. CrossRef Medline

Kenshalo DRG (1968) The skin senses. Springfield, IL: Charles C Thomas.

Kenshalo DR Jr, Isensee O (1983) Responses of primate SI cortical neurons to noxious stimuli. J Neurophysiol 50:1479-1496. Medline

Kenshalo DR Jr, Giesler GJ Jr, Leonard RB, Willis WD (1980) Responses of neurons in primate ventral posterior lateral nucleus to noxious stimuli. J Neurophysiol 43:1594-1614. Medline

Kenshalo DR, Iwata K, Sholas M, Thomas DA (2000) Response properties and organization of nociceptive neurons in area 1 of monkey primary somatosensory cortex. J Neurophysiol 84:719-729. Medline

Krubitzer LA, Kaas JH (1990) The organization and connections of somatosensory cortex in marmosets. J Neurosci 10:952-974. Medline

Lamour Y, Willer JC, Guilbaud G (1983a) Rat somatosensory (SmI) cortex: I. Characteristics of neuronal responses to noxious stimulation and comparison with responses to non-noxious stimulation. Exp Brain Res 49:3545. Medline

Lamour Y, Guilbaud G, Willer JC (1983b) Rat somatosensory (SmI) cortex: II. Laminar and columnar organization of noxious and non-noxious inputs. Exp Brain Res 49:46-54. Medline

Lauria G (1999) Innervation of the human epidermis. A historical review. Ital J Neurol Sci 20:63-70. CrossRef Medline

Lauria G, Holland N, Hauer P, Cornblath DR, Griffin JW, McArthur JC (1999) Epidermal innervation: changes with aging, topographic location, and in sensory neuropathy. J Neurol Sci 164:172-178. CrossRef Medline

Lenz FA, Kwan HC, Martin R, Tasker R, Richardson RT, Dostrovsky JO (1994) Characteristics of somatotopic organization and spontaneous neuronal activity in the region of the thalamic principal sensory nucleus in patients with spinal cord transection. J Neurophysiol 72: 1570-1587. Medline

Liang M, Mouraux A, Iannetti GD (2011) Parallel processing of nociceptive and non-nociceptive somatosensory information in the human primary and secondary somatosensory cortices: evidence from dynamic causal modeling of functional magnetic resonance imaging data. J Neurosci 31: 8976-8985. CrossRef Medline

Maihöfner C, Handwerker HO, Neundörfer B, Birklein F (2003) Patterns of cortical reorganization in complex regional pain syndrome. Neurology 61:1707-1715. CrossRef Medline

Maixner W, Dubner R, Bushnell MC, Kenshalo DR Jr, Oliveras JL (1986) Wide-dynamic-range dorsal horn neurons participate in the encoding 
process by which monkeys perceive the intensity of noxious heat stimuli. Brain Res 374:385-388. CrossRef Medline

Maldjian JA, Gottschalk A, Patel RS, Detre JA, Alsop DC (1999) The sensory somatotopic map of the human hand demonstrated at 4 Tesla. Neuroimage 10:55-62. CrossRef Medline

Mancini F, Longo MR, Iannetti GD, Haggard P (2011) A supramodal representation of the body surface. Neuropsychologia 49:1194-1201. CrossRef Medline

Maxwell DJ, Belle MD, Cheunsuang O, Stewart A, Morris R (2007) Morphology of inhibitory and excitatory interneurons in superficial laminae of the rat dorsal horn. J Physiol 584:521-533. CrossRef Medline

Mazzola L, Isnard J, Peyron R, Guénot M, Mauguière F (2009) Somatotopic organization of pain responses to direct electrical stimulation of the human insular cortex. Pain 146:99-104. CrossRef Medline

McArthur JC, Stocks EA, Hauer P, Cornblath DR, Griffin JW (1998) Epidermal nerve fiber density: normative reference range and diagnostic efficiency. Arch Neurol 55:1513-1520. Medline

McGlone F, Kelly EF, Trulsson M, Francis ST, Westling G, Bowtell R (2002) Functional neuroimaging studies of human somatosensory cortex. Behav Brain Res 135:147-158. CrossRef Medline

Moseley GL, Zalucki NM, Wiech K (2008) Tactile discrimination, but not tactile stimulation alone, reduces chronic limb pain. Pain 137: 600-608. CrossRef Medline

Mountcastle VB, Powell TP (1959) Neural mechanisms subserving cutaneous sensibility, with special reference to the role of afferent inhibition in sensory perception and discrimination. Bull Johns Hopkins Hosp 105: 201-232. Medline

Nelson AJ, Chen R (2008) Digit somatotopy within cortical areas of the postcentral gyrus in humans. Cereb Cortex 18:2341-2351. CrossRef Medline

Overduin SA, Servos P (2004) Distributed digit somatotopy in primary somatosensory cortex. Neuroimage 23:462-472. CrossRef Medline

Penfield W, Rasmussen T (1950) The cerebral cortex of man; a clinical study of localization of function. Oxford: Macmillan.

Ploner M, Schmitz F, Freund HJ, Schnitzler A (2000) Differential organization of touch and pain in human primary somatosensory cortex. J Neurophysiol 83:1770-1776. Medline

Ploner M, Pollok B, Schnitzler A (2004) Pain facilitates tactile processing in human somatosensory cortices. J Neurophysiol 92:1825-1829. CrossRef Medline

Price DD, Greenspan JD, Dubner R (2003) Neurons involved in the exteroceptive function of pain. Pain 106:215-219. CrossRef Medline

Rasmussen T, Penfield W (1947) The human sensorimotor cortex as studied by electrical stimulation. Fed Proc 6:184. Medline

Schlereth T, Magerl W, Treede R (2001) Spatial discrimination thresholds for pain and touch in human hairy skin. Pain 92:187-194. CrossRef Medline

Sereno MI, Huang RS (2006) A human parietal face area contains aligned head-centered visual and tactile maps. Nat Neurosci 9:1337-1343. CrossRef Medline

Sereno MI, Dale AM, Reppas JB, Kwong KK, Belliveau JW, Brady TJ, Rosen BR, Tootell RB (1995) Borders of multiple visual areas in humans revealed by functional magnetic resonance imaging. Science 268: 889-893. CrossRef Medline

Sumner CJ, Sheth S, Griffin JW, Cornblath DR, Polydefkis M (2003) The spectrum of neuropathy in diabetes and impaired glucose tolerance. Neurology 60:108-111. CrossRef Medline

Sur M, Wall JT, Kaas JH (1984) Modular distribution of neurons with slowly adapting and rapidly adapting responses in area $3 \mathrm{~b}$ of somatosensory cortex in monkeys. J Neurophysiol 51:724-744. Medline

Swett JE, Woolf CJ (1985) The somatotopic organization of primary afferent terminals in the superficial laminae of the dorsal horn of the rat spinal cord. J Comp Neurol 231:66-77. CrossRef Medline

Thivierge JP, Marcus GF (2007) The topographic brain: from neural connectivity to cognition. Trends Neurosci 30:251-259. CrossRef Medline

Timmermann L, Ploner M, Haucke K, Schmitz F, Baltissen R, Schnitzler A (2001) Differential coding of pain intensity in the human primary and secondary somatosensory cortex. J Neurophysiol 86:1499-1503. Medline

Todd AJ (2010) Neuronal circuitry for pain processing in the dorsal horn. Nat Rev Neurosci 11:823-836. CrossRef Medline

Treede RD, Kenshalo DR, Gracely RH, Jones AK (1999) The cortical representation of pain. Pain 79:105-111. CrossRef Medline

Valentini E, Hu L, Chakrabarti B, Hu Y, Aglioti SM, Iannetti GD (2012) The primary somatosensory cortex largely contributes to the early part of the cortical response elicited by nociceptive stimuli. Neuroimage 59:1571-1581. CrossRef Medline

Weinberg RJ (1997) Are topographic maps fundamental to sensory processing? Brain Res Bull 44:113-116. CrossRef Medline

Wepsic JG (1966) Multimodal sensory activation of cells in the magnocellular medial geniculate nucleus. Exp Neurol 15:299-318. CrossRef Medline

Yasaka T, Tiong SY, Hughes DI, Riddell JS, Todd AJ (2010) Populations of inhibitory and excitatory interneurons in lamina II of the adult rat spinal dorsal horn revealed by a combined electrophysiological and anatomical approach. Pain 151:475-488. CrossRef Medline

Zhang ZG, Hu L, Hung YS, Mouraux A, Iannetti GD (2012) Gamma-band oscillations in the primary somatosensory cortex-a direct and obligatory correlate of subjective pain intensity. J Neurosci 32:7429-7438. CrossRef Medline 